\title{
Correction to: Surveillance of COVID-19 using a keyword search for symptoms in reports from emergency medical communication centers in Gironde, France: a 15 year retrospective cross-sectional study
}

Cédric Gil-Jardiné ${ }^{1,2} \cdot$ Gabrielle Chenais ${ }^{1,2} \cdot$ Catherine Pradeau $^{1,2} \cdot$ Eric Tentillier $^{2} \cdot$ Phillipe Revel $^{1,2}$. Xavier Combes $^{1,2} \cdot$ Michel Galinski $^{1,2} \cdot$ Eric Tellier $^{1,2} \cdot$ Emmanuel Lagarde $^{1}$ (I)

Published online: 25 August 2021

(c) Società Italiana di Medicina Interna (SIMI) 2021

\section{Correction to: Internal and Emergency Medicine https://doi.org/10.1007/s11739-021-02818-5}

In the original publication of the article, the last author given name and family name was swapped. The correct author name is given in this erratum.

The original article was corrected.

Publisher's Note Springer Nature remains neutral with regard to jurisdictional claims in published maps and institutional affiliations.

The original article can be found online at https://doi.org/10.1007/ s11739-021-02818-5.

Emmanuel Lagarde

emmanuel.lagarde@u-bordeaux.fr

1 Inserm, ISPED, Bordeaux Population Health Research Center Inserm U1219 Injury Epidemiology Transport Occupation Team, Bordeaux cedex, France

2 Inserm, ISPED, Bordeaux Population Health Research Center Inserm U1219 Injury Epidemiology Transport Occupation Team, Pole of Emergency Medicine, University Hospital of Bordeaux, Bordeaux cedex, France 